\title{
Estimation of sources and inflow of Dioxins and Polycyclic Aromatic Hydrocarbons from the sediment core of Lake Suwa, Japan
}

Author names

Yoshinori Ikenaka ${ }^{1}$, Heesoo Eun ${ }^{2}$, Eiki Watanabe ${ }^{2}$, Fujio Kumon ${ }^{3}$, Yuichi Miyabara ${ }^{1}$

Author affiliations

${ }^{1}$ Research and Education Center for Inlandwater Environment, Shinshu University, 5-2-4 Kogandori, Suwa, Nagano 392-0027, Japan,

${ }^{2}$ National Institute for Agro-Environmental Sciences, 3-1-3, Kannondai, Tukuba, Ibaraki 305-8604, Japan,

${ }^{3}$ Department of Environmental Science, Faculty of Sciences, Shinshu University, 3-1-1, Asahi, Matzumoto, Nagano 390-8621, Japan

Corresponding author

Yoshinori Ikenaka

Research and Education Center for Inlandwater Environment, Shinshu University, 5-2-4 Kogandori, Suwa, Nagano 392-0027, Japan.

Telephone numbers: +81-266-52-1955.

Fax number: +81-266-57-1341.

E-mail addresses: s03a601@amail.shinshu-u.ac.jp

Author:Ikenaka, Y; Eun, H; Watanabe, E; Kumon, F; Miyabara, Y

Title:Estimation of sources and inflow of dioxins and polycyclic aromatic hydrocarbons from the sediment core of Lake Suwa, Japan

Journal:ENVIRONMENTAL POLLUTION Vol:138 No.:3 Page:529-537 Year:2005 


\begin{abstract}
To elucidate the historical changes in polychlorinated dibenzo-p-dioxin (PCDD), polychlorinated dibenzofuran (PCDF), coplanar polychlorinated biphenyl (co-PCB), and polycyclic aromatic hydrocarbon (PAH) inflows in Lake Suwa, their concentrations in the sediment core were analyzed in $5 \mathrm{~cm}$ interval. The maximum concentrations (depth $\mathrm{cm}$ ) of PCDDs/DFs, co-PCBs, and PAHs were $25.2 \mathrm{ng} / \mathrm{g}$ dry $(30-35 \mathrm{~cm}), 19.0 \mathrm{ng} / \mathrm{g}$ dry $(30-35 \mathrm{~cm})$, and 738, $795 \mathrm{ng} / \mathrm{g}$ dry $(50-55 \mathrm{~cm}, 30-35 \mathrm{~cm})$, respectively. Age and sedimentation rate of the sediment were estimated from the vertical changes in apparent density. Deposition rate of dioxins and PAHs were calculated from the concentration and sedimentation rate of the sediment. The results indicate that large amounts of dioxins and PAHs flowed into the lake in flood stage compared to normal stage.
\end{abstract}

Capsule

Large amounts of dioxins and PAHs flowed into a lake in flood events

Keywords

Dioxins (PCDDs, PCDFs, co-PCBs), polycyclic aromatic hydrocarbons (PAHs), sediment core, apparent density, deposition rate 


\section{Introduction}

Polychlorinated dibenzo-p-dioxins (PCDDs), polychlorinated dibenzofurans (PCDFs), polychlorinated biphenyls (PCBs), and polycyclic aromatic hydrocarbons (PAHs) are persistent organic chemicals that can bind to the aryl hydrocarbon receptor (Ah-R). These substances may cause similar toxicity in animals. Dioxins (PCDDs/DFs and co-PCBs) and PAHs are hydrophobic chemicals. They tend to be associated with fine particles in the environment, such as soil, suspended solids and suspended particulate matter, and drain into lakes through rivers, and accumulate in the lake sediment (Hegeman et al., 1995; Wakeham et al., 1979). Therefore, the sediment core can represent a record of historical inflow changes of these substances in lakes. Accordingly, to gain a better understanding of the current status of dioxins and PAHs and to develop effective countermeasures to their accumulation, analysis of sediment cores has been widely employed to elucidate their historical trends

The historical changes in deposition rate of dioxins and PAHs have been determined using sediment cores in USA, Europe, and Japan (Chirenzelli et al., 2001; Hosomi et al., 2003; Macdonald et al., 1998; Masunaga et al., 2001a; Rose and Rippey, 2002; Sakai et al., 1999; Sakai et al., 2002; Takeda et al., 2003). These studies used radioactive isotopes (e. g. ${ }^{210} \mathrm{~Pb},{ }^{137} \mathrm{Cs}$ ) to determine sedimentation rates in aquatic environment. Although these methods were very effective for age determination, they could not evaluate event sedimentation such as flooding or heavy rain, when sedimentation rate may increase instantly, with large amounts of chemicals flowing into the aquatic environments.

In the present study, we identify flood sediment layers in a cored sediments core taken from Lake Suwa, Japan, which enables us to determine precise sediment age and flood impact on sediment. Then we show the vertical changes of dioxin and PAH contents in the sediment core at an interval of $5 \mathrm{~cm}$. Using the sedimentation rate and vertical distribution of chemicals, we can estimate the annual input of dioxins and PAHs, and the historical inflows of these chemicals into Lake Suwa.

\section{Materials and Methods}

2.1. Study area.

Lake Suwa is located in a rural mountainous area in Japan $\left(36^{\circ} 3^{\prime} \mathrm{N}, 138^{\circ} 5^{\prime} \mathrm{E}\right)$ with an average depth of $4.0 \mathrm{~m}$ and a maximum depth of $6.3 \mathrm{~m}$ (Fig. 1). Its surface and drainage areas are 13.3 and $531 \mathrm{~km}^{2}$, respectively. About $12 \%$ of the drainage area is utilized for agricultural purposes, about $10 \%$ is given over to commercial and residential areas, and the rest is forest. The area around Lake Suwa is famous for silk production in former time, and for mechanical and electric industries in the recent.

\subsection{Cored sediment.}

The bottom sediment was cored carefully into an acryle tube of $58 \mathrm{~mm}$ diameter and 1 meter length at the center of Lake Suwa by the scuba divers on 01 August 2003. Several cored samples were taken at the same point at same time to synthesize and compare various data. The cored sample of this study is $79 \mathrm{~cm}$ long, and was split lengthwise in the laboratory. The cored sediment was stratified without any artificial disturbance. After observation and description on the cut surface by naked-eyes, a half of the cored sediment is cut at $1 \mathrm{~cm}$ interval. The wet weight and dry weight of each section was measured. 
Another half was used for analysis of dioxins (PCDDs/DFs, co-PCBs) and PAHs in $5 \mathrm{~cm}$ interval.

\subsection{Apparent density.}

The apparent density $(\mathrm{Da})$ is solid weight per unit volume of sediment, postulating grain density as 2.65 which is equivalent to quartz density and interstitial water density as 1.0 $\mathrm{g} / \mathrm{cm}^{3}$. The formula is as follows.

$\mathrm{Da}=$ Wdry / (Wdry /2.65 +(Wwet - Wdry ) / 1)

Da: apparent density $\left(\mathrm{g} / \mathrm{cm}^{3}\right)$, Wdry: dry weight, Wwet: wet weight

Wet weight is measured as quickly as possible after deviding into $1 \mathrm{~cm}$ interval, and dry weight is measured after 12 hours drying in an oven at $105{ }^{\circ} \mathrm{C}$. Apparent density can reflect sensitively grain size and/or compactness of grain packing (Adhikari and Kumon, 2001; Kumon et al., 2004).

\subsection{Analysis of Dioxins.}

Sediment was treated according to the method described by Miyabara et al. (1999). Briefly, samples of approximately $20 \mathrm{~g}$ of sediment were air-dried at room temperature and soxhlet extracted with toluene for $18 \mathrm{~h}$. After extraction, these extracts were divided into two fractions for doxin and PAH analysis (dioxins:PAHs $=9: 1(\mathrm{v} / \mathrm{v})$ ). The fraction for dioxin analysis was spiked with ${ }^{13} \mathrm{C}$ labeled PCDDs/DFs and co-PCBs as internal standards (Wellington Laboratories). Then, the extract was cleaned and fractionated by silica gel and activated carbon column chromatography. The amounts of dioxins were measured by HRGC/HRMS (Agilent 6890 plus/Micromass Autospec-Ultima) equipped with capillary columns (SP-2331 (Supeluco) for Te-HxCDDs/DFs, DB-5/MS (Agilent) for HpOCDDs/DFs and co-PCBs).

\subsection{Analysis of PAHs.}

PAH in sediment was analyzed according to the method described by Wakeham et al. (1979). Briefly, the fraction for PAH analysis was spiked with deuterated PAHs as internal standards (Ehrenstorfer $\mathrm{GmbH}$ ) and cleaned up by silica gel column chromatography. The PAH concentration was measured by GC/MS (Shimadzu QP5050A), equipped with a DB5/MS capillary column. Quantification of 17 PAHs (Naphthalene [Nap], Acenaphthylene [Acl], Acenaphthene [Ace], Fluorene [Fle], Phenanthrene [Phe], Anthracene [Ant], Fluoranthene [Flu], Pyrene [Pyr], Benzo[a]anthracene [BaA], Chrysene [Chr], Benzo[k]fluoranthene [BkF], Benzo[b]fluoranthene [BbF], Benzo[e]pyrene [BeP], Benzo[a]pyrene [BaP], Indeno[1,2,3-cd]pyrene [IDP], Dibenzo[ah]anthrathene [DBahA], Benzo[ghi]perylene [BghiP]) were determined from calibration curves made by standards (AccuStandard Inc). Total amounts of PAHs were calculated as the total of 17 PAHs.

\section{Results}

4.1. Sedimentation rate and age determination of cored sediment.

Vertical profile of apparent density of the sediment cored in AD 2003 is shown in Figure 2. This profile is characterized of a downward increasing trend with some sudden peaks. The concentration profile of ${ }^{137} \mathrm{Cs}$ is also shown in the figure (H. Fukushima, personal com.). ${ }^{137} \mathrm{Cs}$, an artificial radioactive, is first found in sediment in AD 1954, and its 
concentration peak corresponds with AD 1963 usually (Kanai and Ikehara, 1995). The ${ }^{137} \mathrm{Cs}$ measurement was performed for another sediment core in 2.5 or $5 \mathrm{~cm}$ interval, which was sampled at the same time and same locality. Although these exist a slight discordance, a few to several centimeters, in depth due to artificial treatment, these ages are good reference to determine sediment age. Additionally, when this density profile is compared with that of cored sediment in AD 1974 by Hayashi (1983), the profiles are very similar with each other, but the uppermost peak around $25 \mathrm{~cm}$ depth is lack in the core of 1974 . Then, the uppermost density peak must be younger than AD 1974.

The heavy rains and associated water level changes of the lake are listed in Table 1 (Kitahara, 1992). Large flood caused by heavy rain can transport coarser and denser materials than the usual ones even into the lake center as density flow sediment (Sturm and Matter, 1978). Under the above-mentioned age framework, we can safely correlate the density peaks to the large floods, that is, peak around $26 \mathrm{~cm}$ depth to flood on 28 September 1983, $47 \mathrm{~cm}$ to 29 June 1961, and $62 \mathrm{~cm}$ to 10 June 1950, respectively. Accounting for bioturbation effect, flood sediments are regarded as relatively thinner parts such as 21-28 cm = flood in 1983, 40-49 cm = flood in 1961, and 58-63 cm = flood in 1950 (Fig. 3). Sedimentation rates are also postulated as constant between the flood events. We regard the sedimentation rate below $64 \mathrm{~cm}$ depth is the same as those between the floods of 1950 and 1961. Based on the above-mentioned sedimentation rates, we can convert the sediment depth into the age of deposition. The estimated ages of sediment sections used for chemical analysis are listed in Table 2. Sedimentation rates except for during flood events are almost constant within a range of 0.16 to $0.24 \mathrm{~g} / \mathrm{cm}^{2} /$ year during the last 80 years.

\subsection{Vertical changes in concentrations of Dioxins and PAHs.}

Vertical variations in dioxin and PAH concentrations in the sediment core are shown in Figure 3. Marked increases in PCDDs/PCDFs concentrations were observed from the section of 35-40 cm, and the maximum concentration (22.4 ng/g dry) was observed at 30$35 \mathrm{~cm}$. The concentration decreased gradually toward the surface. Major homologues of PCDDs/DFs at the depth of 35-40 cm were OCDD and HpCDDs, which accounted for $90 \%$ of the total amount of PCDDs/DFs (Figure 4). TeCDDs and PeCDDs were also detected in the sediment core. These concentrations increased above a depth of 30-35 cm, and its maximum concentration, which accounted for $15 \%$ of the total amount of PCDDs/DFs, was observed at 20-25 cm (Figure 3, 4). On the other hand, the concentration of PCDFs was low in all sections, and was $2-30 \%$ of total amount of PCDDs/DFs (Figure $3,4)$.

Increases in co-PCB concentration were observed in the $50-55 \mathrm{~cm}$ section, and it reached the maximum concentration (19.0 ng/g dry) at 30-35 cm (Fig. 4). Then, the concentrations of co-PCBs decreased gradually toward the surface. The homologue and congener profile of co-PCBs was similar among all sections of sediment core. Major congeners of co-PCBs were 2,3',4,4',5-PeCB (IUPAC \#118), 2,3,3’,4,4'-PeCB (\#105) and 3,3',4,4'-TeCB (\#77), accounting for about $50 \%$ of co-PCBs (Fig. 5).

Two peaks of PAH concentration were observed in the sections from $50-55 \mathrm{~cm}(738 \mathrm{ng} / \mathrm{g}$ dry) and 30-35 cm (795 ng/g dry) (Fig. 4). The PAH profile was similar among all sections of sediment core. Major PAHs in the sediment were Phe, Flu, Pyr, and BbF (Fig. 6). 


\section{Discussion}

\subsection{Sources of Dioxins and PAHs in Lake Suwa.}

PCDDs/DFs. A marked increase in the concentration of PCDDs/DFs was observed in the section from 35-40 cm, which was estimated to be from 1961-1970. The major congeners were OCDD and HpCDDs. It was reported that OCDD and HpCDDs were impurities of pentachlorophenol (PCP) (Masunaga et al., 2001b). A large quantity of PCP was used as paddy field herbicide in Japan from 1955 to1974 (Masunaga et al., 2001b). These results suggested that one of the major sources of PCDDs/DFs in sediment from Lake Suwa was PCP, and the increase in its level reflected the use of PCP in paddy fields in Suwa. On the other hand, the maximum concentrations of TeCDDs and PeCDDs were observed in section 20-25 cm, which was estimated to be from 1983. Major congeners of these homologues were 1,3,6,8- and 1,3,7,9-TeCDD and 1,2,4,7,9-, 1,2,3,6,8- and 1,2,3,7,9PeCDD. These congeners were reported to be mainly chloronitrophen (CNP), and large quantities of CNP were used as paddy field herbicide in Japan from 1965 to 1994 (Masunaga et al., 2001b). Thus, the increases in levels of TeCDDs and PeCDDs in the sediment core from Lake Suwa were dependent on the use of CNP. Similarly, high concentrations of PCDDs/DFs in sediment, which were dependent on the historic use of PCP and CNP in paddy fields, were observed in other parts of Japan, such as Osaka Bay, Tokyo Bay, Lake Biwa, and Lake Shinji (Hosomi et al., 2003; Masunaga et al., 2001a; Sakai et al., 1999; Sakai et al., 2002; Takeda et al., 2003). These results and those of the present study indicated that the PCDD contamination in the sediment was dependent on the historic use of PCP and CNP.

On the other hand, the concentration of PCDFs was lower than that of PCDDs in all sections. It is well known that lower levels of chlorinated PCDFs are synthesized in combustion processes (Iino et al, 2001; Rappe et al, 1978; Sakai et al, 1993; Vogg and Stieglitz, 1986; Wilken et al, 1992). The major source of PCDFs in the sediment core from Lake Suwa was considered to be combustion. However, the contribution of PCDFs from combustion to the total amount of PCDDs/DFs was small.

co-PCBs. The concentration of co-PCBs increased in the section from 50-55 cm and reached their peak in the section from $30-35 \mathrm{~cm}$. These sections were estimated to be from 1954-1959 and 1971-1979, respectively. It was reported previously that commercial PCB products, such as transformers and capacitors, contained co-PCBs. A total of $5.7 \times 10^{7} \mathrm{~kg}$ of PCBs was synthesized from 1954 to 1972 in Japan (Takasuga et al., 1995). The largest amounts of PCBs were used in 1970, and its use was prohibited in 1974 in Japan. On the other hand, major isomers of co-PCBs in sediment from Lake Suwa were \#118, \#115, and \#77, and these isomers were the major components of the PCB products (Takasuga et al., 1995; Sather et al., 2001). These results suggested that the major source of co-PCBs in the sediment core from Lake Suwa was commercial PCB products.

The synthesis of PCBs began in 1954 in Japan. However, co-PCBs were detected in lower sections of the core estimated to be from before 1950. This may be dependent on the by-products of incineration (Ikonou et al., 2002; Sakai et al., 2001) or vertical transportation through the interstitial water in the sediment core (Bopp et al., 1982).

PAHs. Two maximum concentrations of PAHs were observed at 50-55 cm and 30-35 cm, and these sections were estimated to be from 1954-1959 and 1971-1979, respectively. The profiles of PAHs were relatively similar in all sections. The major sources of PAHs are the exhausts of diesel and gasoline engine vehicles, tires, and road materials (Liu et al., 2000; 
Marr et al., 1999; Pengchai et al., 2002). It was reported previously that each source of PAHs has a characteristic pattern (Zheng et al., 2002) and the usefulness of PAH isomer ratios, such as Phe/Ant (tricyclic aromatics; MW 178), Pyr/Flu (tetracyclic aromatics; MW 202), and BeP/BaP (pentacyclic aromatics; MW 252), was demonstrated for source identification. As Phe is more stable thermodynamically than Ant, the ratio of Phe/Ant reflects the origin of PAHs, petrogenic or pyrogenic in the environment. Petrogenic PAH was generally characterized by a high ratio of Phe/Ant (normally $>15$ ), while pyrogenic had a lower ratio. The ratio of Phe/Ant was $4.1 \pm 0.8$ (average $\pm S D, n=16$ ) in the sediment core from Lake Suwa. Accordingly, the major source of PAHs in the sediment was considered to be pyrogenic.

\subsection{Depositions of Dioxins and PAHs.}

We calculated the annual flux ( $\mathrm{pg} / \mathrm{cm}^{2} / \mathrm{yr}$ ) of dioxins and PAHs in Lake Suwa from these concentrations and sedimentation rate in each section of the core (Table 3). In addition, we also calculated 2,3,7,8-TCDD toxic equivalent quantity (TEQ-pg/g) of each section and annual deposition rate represented by TEQ (pg-TEQ/cm²/yr). TEQ of each section was estimated by both TEFs (Toxic equivalent factor) for dioxins and PAHs established by WHO and Till et al. (1999), respectively (Table 3). To our knowledge, this is the first report of the effect of flooding on the deposition flux of dioxins and PAHs in sediment core.

Total amounts of PCDDs/DFs, Co-PCBs, and PAHs that input to the lake between 1923 and 2003 were $109 \mathrm{ng} / \mathrm{cm}^{2}$ (273 pg-TEQ/ $\left./ \mathrm{cm}^{2}\right), 59 \mathrm{ng} / \mathrm{cm}^{2}\left(26 \mathrm{pg}-\mathrm{TEQ} / \mathrm{cm}^{2}\right)$, and 7.4 $\mu \mathrm{g} / \mathrm{cm}^{2}$ (260 $\mathrm{pg}-\mathrm{TEQ} / \mathrm{cm}^{2}$ ), respectively. These results indicated that the contribution of PAHs to the total amount of TEQ in the sediment core was high, 10-fold as higher than coPCBs and almost similar to PCDDs/DFs. And this high contribution of PAHs was matched reasonably well to those reported by Kannan et al. (2001) and Eljarrat et al. (2001). On the other hand, the average values of annual influx of PCDDs/DFs, co-PCBs, and PAHs were $1.3 \mathrm{ng} / \mathrm{cm}^{2} / \mathrm{yr}\left(3.3 \mathrm{pg}-\mathrm{TEQ} / \mathrm{cm}^{2} / \mathrm{yr}\right), 0.7 \mathrm{ng} / \mathrm{cm}^{2} / \mathrm{yr}\left(0.3 \mathrm{pg}-\mathrm{TEQ} / \mathrm{cm}^{2} / \mathrm{yr}\right)$, and $88 \mathrm{ng} / \mathrm{cm}^{2} / \mathrm{yr}$ (3.1 $\left.\mathrm{pg}-\mathrm{TEQ} / \mathrm{cm}^{2} / \mathrm{yr}\right)$, respectively. It was reported that the levels of deposition flux of PCDDs/DFs in Osaka Bay and Lake Biwa, located in urban areas in Japan, were 1-3 $\mathrm{ng} / \mathrm{cm}^{2} / \mathrm{yr}$ and $1 \mathrm{ng} / \mathrm{cm}^{2} / \mathrm{yr}$, respectively. In addition, Lake Shiraike and Lake Takanaminoike, located in rural areas in Japan, had fluxes of $0.002-0.02 \mathrm{ng} / \mathrm{cm}^{2} / \mathrm{yr}$ and $0.01 \mathrm{ng} / \mathrm{cm}^{2} / \mathrm{yr}$, respectively (Sakai et al., 1999; Sakai et al., 2002). Lake Suwa is located in a rural area. However, the PCDD/DF deposition flux was similar to that in Osaka Bay. This might reflect the drainage area of Lake Suwa, because the ratio of lake and drainage area of Lake Suwa (40-fold) was larger than those of other lakes (Lake Shinji: 15-fold, Lake Biwa: 7-fold) in Japan.

Furthermore, we estimated the effects of floods on the inflow of dioxins and PAHs in Lake Suwa. The annual deposition of PCDDs/DFs in Lake Suwa was $19 \mathrm{ng} / \mathrm{cm}^{2} / \mathrm{yr}$ (43 pg$\mathrm{TEQ} / \mathrm{cm}^{2} / \mathrm{yr}$ ) in 1983, when heavy floods occurred (precipitation, $156 \mathrm{~mm} /$ day September 1982, $216 \mathrm{~mm} /$ day September 1983), and corresponded to $17 \%$ (16 \%-TEQ) of total inflow of PCDDs/DFs into the lake between 1923 and 2003. Further, the levels of deposition of co-PCBs were high in 1961 and 1983, with values of $3 \mathrm{ng} / \mathrm{cm}^{2} / \mathrm{yr}$ (1 pg$\left.\mathrm{TEQ} / \mathrm{cm}^{2} / \mathrm{yr}\right)$ and $7 \mathrm{ng} / \mathrm{cm}^{2} / \mathrm{yr}\left(6 \mathrm{pg}-\mathrm{TEQ} / \mathrm{cm}^{2} / 2 \mathrm{yr}\right)$, respectively. A large flood occurred in 1961 (precipitation, $369 \mathrm{~mm} /$ day June), and both contribution of 1961 and 1983 inflows were estimated to be $18 \%$ (25 \%-TEQ) of total inflows of co-PCBs. Similarly, the deposition of PAHs was high in the years in which floods occurred: i.e., 1950 (precipitation, 
$231 \mathrm{~mm} /$ day June), 1961, and 1983, with annual deposition of $0.4 \mu \mathrm{g} / \mathrm{cm}^{2} / \mathrm{yr}$ (15 pg$\left.\mathrm{TEQ} / \mathrm{cm}^{2} / \mathrm{yr}\right), 0.5 \mu \mathrm{g} / \mathrm{cm}^{2} / \mathrm{yr}\left(16 \mathrm{pg}-\mathrm{TEQ} / \mathrm{cm}^{2} / \mathrm{yr}\right)$, and $0.6 \mu \mathrm{g} / \mathrm{cm}^{2} / \mathrm{yr}\left(19 \mathrm{pg}-\mathrm{TEQ} / \mathrm{cm}^{2} / 2 \mathrm{yr}\right)$, respectively. In addition, these contributions to the total inflow of PAHs were estimated to be 6,6 , and $8 \%$ (6, 6, $7 \%$-TEQ), respectively. These results indicated that large quantities of dioxins and PAHs flowed into the lake in flood stages.

The results of the present study indicated that a large quantity of substances flowed into the lake in flood stages as compared to the normal stage. However, recent environmental monitoring studies did not take into account floods or heavy rain. Therefore, it is necessary to determine the aquatic environment at all stages (floods or heavy rain) as well as in the normal stage.

\section{Conclusions}

The history of contamination by dioxins agreed with the age determination of the sediment core based on apparent density (Da). The results of the present study indicated that the major sources of dioxins were chemical products that were used widely in Japan more than 20 years ago. PCDDs/DFs and PCBs remained in drainage areas, and flowed continuously into the aquatic environment despite the application bans of PCP, CNP, and PCBs. PAHs in the lake sediments were mainly of pyrogenic origin. However, unlike the PCDDs/DFs and co-PCBs, it was not possible to determine the sources of PAHs clearly. On the other hand, both total amount and TEQ of PAHs were higher than those of co-PCBs. And TEQ of PAHs was almost similar to that of PCDDs/DFs. Furthermore, we estimated the annual deposition flux of each substance. The results indicated that large quantities of PCDDs/DFs, co-PCBs, and PAHs flowed into the lake during periods of flooding. The environment in the flood stage was considered to be completely different to that in the normal stage. Therefore, countermeasures to environmental contamination by these compounds should be determined not only for the normal stage but also for event stages, such as flooding.

Acknowledgements

The authors are grateful to T. Fukushima, M. Ohta, T. Tawara, and K. Kise for their collaboration in this study. 
References

Adhikari, D. P., Kumon, F. Limnology 2001, 2, 157-168

Bopp, R. F., Simpson, H. J., Olsen, C. R., Trier, R. M., Kostyk, N. Environ. Sci. Technol. 1982, 16, 666-676

Chiarenzelli, R. J., Alexander, C., Isley, A., Scrudato, R., Pagano, J., Ramirez, W. Environ. Sci. Technol. 2001, 35, 2903-2908

Eljarrat, E., Caixach, J., Rivera, J. Environ. Sci. Technol. 2001, 35, 18, 3589-3594

Hayashi, H. Tokyo Metropolitan University 1983

Hegeman, J. M. W., Weijden, H. V. D. C., Loch, P. G. J. Environ. Sci. Technol. 1995, 29, 363-371

Hosomi, M., Matsuo, T., Dobashi, S., Katou, S., Abe, H. Marine Pollution Bulletin 2003, 47, 68-73

Iino, F., Tsuchiya, K., Imagawa, T., Gullett, K. B. Environ. Sci. Technol. 2001, 35, 31753181

Ikonomou, G. M., Sather, P., Oh, J., Choi, W., Chang, Y. Chemosphere 2002, 49, 205-216

Kanai, Y., Ikehara, K. Bull. Geol. Surv. Japan 1995, 46, 269-282.

Kannan, K., Villeneuve, D., Yamashita, N., Imagawa, T., Hashimoto, S., Miyazaki, A., Giesy, J. Environ. Sci. Technol. 1999, 33, 4206-4211.

Kumon, F., Tawara, T., Yamamoto, M. Research Report of the Research and Education Center for Inlandwater Environment Shinshu University 2004, 3, 77-84

Kitahara, Y., the Ministry of Construction Suwako 1992, 39-42

Liu, K., Xie, W., Zhao, Z., Pan, W., Riley, J. Environ. Sci. Technol. 2000, 34, 2273-2279

Macdonald, W. R., Ikonomou, G. M., Paton, W. D. Environ. Sci. Technol. 1998, 32, 331337

Marr, C. L., Kirchstetter, W. T., Harley, A. R., Miguel. H. A., Hering, V. S., Hammond, K. S. Environ. Sci. Technol. 1999, 33, 3091-3099

Masunaga, S., Yao, Y., Ogura, I., Nakai, S., Kanai, Y., Yamamoto, M., Nakanishi, J. Environ. Sci. Technol. 2001a, 35, 1967-1973

Masunaga, S., Takasuga, T., Nakanishi, J. Chemosphere 2001b, 44, 873-885

Miyabara, Y., Hashimoto, S., Sagai, M., Morita, M. Chemosphrere 1999, 39, 143-150

Pengchai, P., Nakajima, F., Furumai, H. Environmental Science 2002, 15, 433-442

Rappe, C., Gara, A., Buser, R. H. Chemosphere 1978, 12, 981-991

Rose, L. N., Rippey, B. Environmental Pollution 2002, 117, 121-132

Sakai, S., Deguchi, S., Takatuki, H. Environmental Science 2002, 15, 361-376

Sakai, S., Deguchi, S., Urano, S., Takatuki, H., Megumi, K. Journal of Environmental Chemistry 1999, 9, 379-390

Sakai, S., Hayakawa, K., Takatsuki, H., Kawakami, I. Environ. Sci. Technol. 2001, 35, 3601-3607

Sakai, S., Hiraoka, M., Takeda, N. Shiozaki, K. Chemosphere 1993, 27, 233-240

Sather, J. P., Ikonomou, G. M., Addison, F. R., He, T., Ross, S. P., Fowler, B. Environ. Sci. Technol. 2001, 35, 4874-4880

Sturm, M., Matter, A. Spec. Publs int. Ass. Sediment. 1978, 2, 147-168

Takasuga, T., Inoue, T., OHI, E. Journal of Environmental Chemistry 1995, 5, 647-675

Takeda, Y., Kassai, K., Iimura, F., Tukui, T., Yoshioka, H., Higashino, K., Sasaki, Y. Journal of Environmental Chemistry 2003, 13, 397-407 
Till, M., Riebniger, D., Schmitz, H. J., Schrenk, D. Chem. Biol. Interact. 1999, 117, 135150

Vogg, H., Stieglitz, L. Chemosphere 1986, 15, 1373-1378

Wakeham, G. S., Schaffner, C., Giger, W. Geochimica et Cosmochimica Acta 1979, 44, 403-413

Wilken, M., Cornelsen, B., Zeschmar-Lahl, B., Jager, J. Chemosphere 1992, 25, 1517-1523

Zheng, J. G., Man, W. K. B., Lam, W. C. J., Lam, W. H. L., Lam, K. S. P. Water Research 2002, 36, 1457-1468 
Table 1: Records of precipitation and floods in Suwa area

\begin{tabular}{|c|c|c|c|c|c|}
\hline \multirow[b]{2}{*}{ Year/Month/Day } & \multicolumn{2}{|c|}{$\begin{array}{l}\text { Total contineous } \\
\text { precipitation }(\mathrm{mm})\end{array}$} & \multicolumn{2}{|c|}{ Water level change $(\mathrm{cm})$} & \multirow{2}{*}{$\begin{array}{l}\text { Flood } \\
\text { impact }\end{array}$} \\
\hline & $\begin{array}{l}\text { Total } \\
\text { amount }\end{array}$ & $\begin{array}{l}\text { One day } \\
\text { maximum }\end{array}$ & $\begin{array}{l}\text { Maximum } \\
\text { water level }\end{array}$ & \begin{tabular}{|c|} 
Increasing of \\
water level \\
per event
\end{tabular} & \\
\hline 1948/JUN./14-17 & 123 & $6 / 14 \quad 63$ & 127 & 42 & \\
\hline 1949/SEP./21- 23 & 151 & $9 / 23 \quad 134$ & 147 & 45 & \\
\hline $1950 / J U N . / 9-15$ & 282 & $6 / 11 \quad 100$ & 221 & 111 & 0 \\
\hline $1951 / J U L . / 11-16$ & 166 & $7 / 15 \quad 71$ & 156 & 62 & \\
\hline 1956/AUG./28-31 & 185 & $8 / 29 \quad 55$ & 142 & 44 & \\
\hline 1957/JUN./27- 29 & 126 & $6 / 27 \quad 66$ & 146 & 40 & \\
\hline 1957/SEP./9- 12 & 105 & $\begin{array}{ll}9 / 10 \quad 52 \\
\end{array}$ & 145 & 45 & \\
\hline 1958/JUL./21- 27 & 126 & $7 / 26 \quad 42$ & 132 & 47 & \\
\hline 1959/AUG./12-14 & 136 & $8 / 14 \quad 71$ & 192 & 98 & \\
\hline 1959/SEP./13 14 & 119 & $9 / 14 \quad 101$ & 137 & 41 & \\
\hline 1959/SEP./25- 28 & 139 & $9 / 26 \quad 52$ & 155 & 58 & \\
\hline $1961 / J U N . / 23-30$ & 368 & $6 / 28 \quad 111$ & 253 & 159 & 0 \\
\hline 1965/JUL./12-13 & 102 & $7 / 13 \quad 82$ & 157 & 63 & \\
\hline 1965/SEP./14 18 & 122 & $9 / 17 \quad 98$ & 159 & 67 & \\
\hline 1966/SEP./22- 24 & 172 & $9 / 22 \quad 76$ & 140 & 40 & \\
\hline 1967/JUL./9-11 & 186 & $\begin{array}{ll}7 / 9 & 110 \\
\end{array}$ & 204 & 106 & 0 \\
\hline 1968/AUG./26- 29 & 169 & $8 / 28 \quad 97$ & 141 & 43 & \\
\hline 1970/JUN./14 16 & 180 & $6 / 15 \quad 97$ & 147 & 76 & \\
\hline 1971/SEP./6- 7 & 192 & $9 / 6 \quad 119$ & 133 & 55 & \\
\hline 1972/JUL./9-15 & 286 & $7 / 10 \quad 121$ & 140 & 71 & \\
\hline 1974/APR./7- 9 & 127 & $4 / 8 \quad 92$ & 121 & 67 & \\
\hline 1980/JUL./6- 9 & 155 & $7 / 8 \quad 103$ & 138 & 67 & \\
\hline 1981/JUL./1- 4 & 149 & $7 / 2 \quad 68$ & 123 & 49 & \\
\hline 1982/JUL./29-AUG./3 & 176 & $8 / 1 \quad 81$ & 172 & 87 & \\
\hline 1982/SEP./8 12 & 232 & $9 / 12 \quad 95$ & 198 & 126 & \\
\hline 1983/SEP./27- 28 & 216 & $9 / 28 \quad 162$ & 240 & 167 & 0 \\
\hline 1985/JUN./20- 26 & 133 & $6 / 25 \quad 54$ & 197 & 125 & \\
\hline
\end{tabular}

Precipitation data and floods data were referenced to Japan Meteorological Agency and Construction Office of Nagano Prefecture, respectively.

*Precipitation of one day maximum $>100 \mathrm{~mm}$, Increasing of water level per event $>100 \mathrm{~cm}$ 
Table 2. Age and sedimentation rate of the sediment core in each section

\begin{tabular}{|c|c|c|}
\hline Depth & $\begin{array}{c}\text { Corresponding } \\
\text { year }\end{array}$ & $\begin{array}{c}\text { Sedimentation rate } \\
\mathrm{g} / \mathrm{cm}^{2} / \mathrm{yr}\end{array}$ \\
\hline $0-5$ & $2000-2003$ & \multirow{5}{*}{ S/uim/yi } \\
\hline 5- 10 & 1995- 1999 & \\
\hline 10 15 & 1990 1994 & \\
\hline 15. 20 & 19841989 & \\
\hline $20-21$ & 1983 & \\
\hline $21-28$ & flood (1983) & \\
\hline 2830 & $1980-1982$ & \multirow{3}{*}{0.16} \\
\hline $30-35$ & 1971- 1979 & \\
\hline $35-40$ & 1961- 1970 & \\
\hline $40-49$ & flood (1961) & \\
\hline 49-50 & 1960 & \multirow{3}{*}{0.24} \\
\hline $50-55$ & 19541959 & \\
\hline 55- 58 & 1950-1953 & \\
\hline 5863 & flood (1950) & \\
\hline 6365 & 1947- 1949 & \multirow{4}{*}{0.24} \\
\hline $65-70$ & 1939-1946 & \\
\hline $70-75$ & 1930-1938 & \\
\hline 75- 79 & 1923 1929 & \\
\hline Average & & $\begin{array}{c}0.33 \mathrm{~g} / \mathrm{cm}^{2} / \mathrm{yr} \\
0.98 \mathrm{~cm} / \mathrm{yr}\end{array}$ \\
\hline
\end{tabular}


Table 3. Annual deposition flux of dioxins and PAHs

\begin{tabular}{|c|c|c|c|}
\hline $\begin{array}{c}\text { Corresponding year } \\
\text { (AD) }\end{array}$ & $\begin{array}{c}\text { PCDDs/DFs } \\
\mathrm{ng} / \mathrm{cm}^{2} / \mathrm{yr} \text { (pg- TEQ) }\end{array}$ & $\begin{array}{c}\text { co- PCBs } \\
\mathrm{ng} / \mathrm{cm}^{2} / \mathrm{yr}(\mathrm{pg}-\mathrm{TEQ})\end{array}$ & $\begin{array}{c}\text { PAHs } \\
\mathrm{ng} / \mathrm{cm}^{2} / \mathrm{yr}(\mathrm{pg}-\mathrm{TEQ})\end{array}$ \\
\hline $2000-2003$ & $1.27(6.75)$ & $0.44(0.25)$ & $46(2.96)$ \\
\hline 1995- 1999 & 1.46 (4.47) & 0.34 (0.35) & 40 (2.42) \\
\hline 1990-1994 & 1.58 (4.36) & 0.36 (0.35) & 46 (2.44) \\
\hline $1984-1989$ & 1.91 (4.98) & 0.45 (0.44) & 50 (2.25) \\
\hline 1983 & 0.37 (0.83) & $0.10(0.09)$ & 10 (0.36) \\
\hline 1980-1982 & 0.85 (1.87) & $0.43(0.29)$ & $27(0.90)$ \\
\hline 1971- 1979 & $4.04(7.22)$ & 3.05 (1.04) & 127 (3.62) \\
\hline 1961- 1970 & 1.64 (3.49) & $1.08(0.11)$ & 99 (2.80) \\
\hline 1960 & $0.00(0.04)$ & $0.02(0.01)$ & $6(0.21)$ \\
\hline 19541959 & $0.06(0.72)$ & $0.20(0.09)$ & 177 (5.39) \\
\hline 1950- 1953 & 0.06 (0.43) & $0.02(0.02)$ & 108 (2.06) \\
\hline 1947- 1949 & $0.01 \quad(0.10)$ & 0.00 (0.00) & 31 (1.09) \\
\hline $1939-1946$ & 0.02 (0.44) & $0.01 \quad(0.02)$ & 87 (2.99) \\
\hline 1930-1938 & $0.06(0.47)$ & $0.02(0.01)$ & 37 (1.81) \\
\hline 1923-1929 & $0.02(0.38)$ & $0.00(0.02)$ & 27 (1.76) \\
\hline flood (1983) & 19.06 (42.53) & 7.38 (5.57) & 552 (19.34) \\
\hline flood (1961) & 0.76 (4.08) & 2.74 (0.91) & 457 (15.59) \\
\hline flood (1950) & $0.24(2.13)$ & $0.11(0.09)$ & 422 (14.72) \\
\hline $\begin{array}{c}\text { average } \\
\text { total(ng)(pg- TEQ) }\end{array}$ & $\begin{array}{ll}1.30 & (3.25) \\
109 & (273)\end{array}$ & $\begin{aligned} 0.71 & (0.31) \\
59 & (26)\end{aligned}$ & $\begin{aligned} 88 & (3.09) \\
7381 & (260)\end{aligned}$ \\
\hline
\end{tabular}

Annual deposition flux was calculated using concentration of these substances and sedimentation rate in each section. TEQ (PCDDs/DFs, co-PCBs) were calculated using the WHO-TEFs for human (WHO, 1997). TEQ (PAHs) were calculated using the TEFs Till et al. (1999) proposed (1.00, 6.17E-8, 9,25E-8, 2.22E-6, 5.61E-6, 2.03E-4, 3.52E-5, 2.12E-5, 5.80E-5, 1.17E-4 and 9.25E-8 for 2,3,7,8-TCDD, Ace, Flu, BaA, Chr, BkF, BbF, BaP, IDP, DBahA and BghiP). 


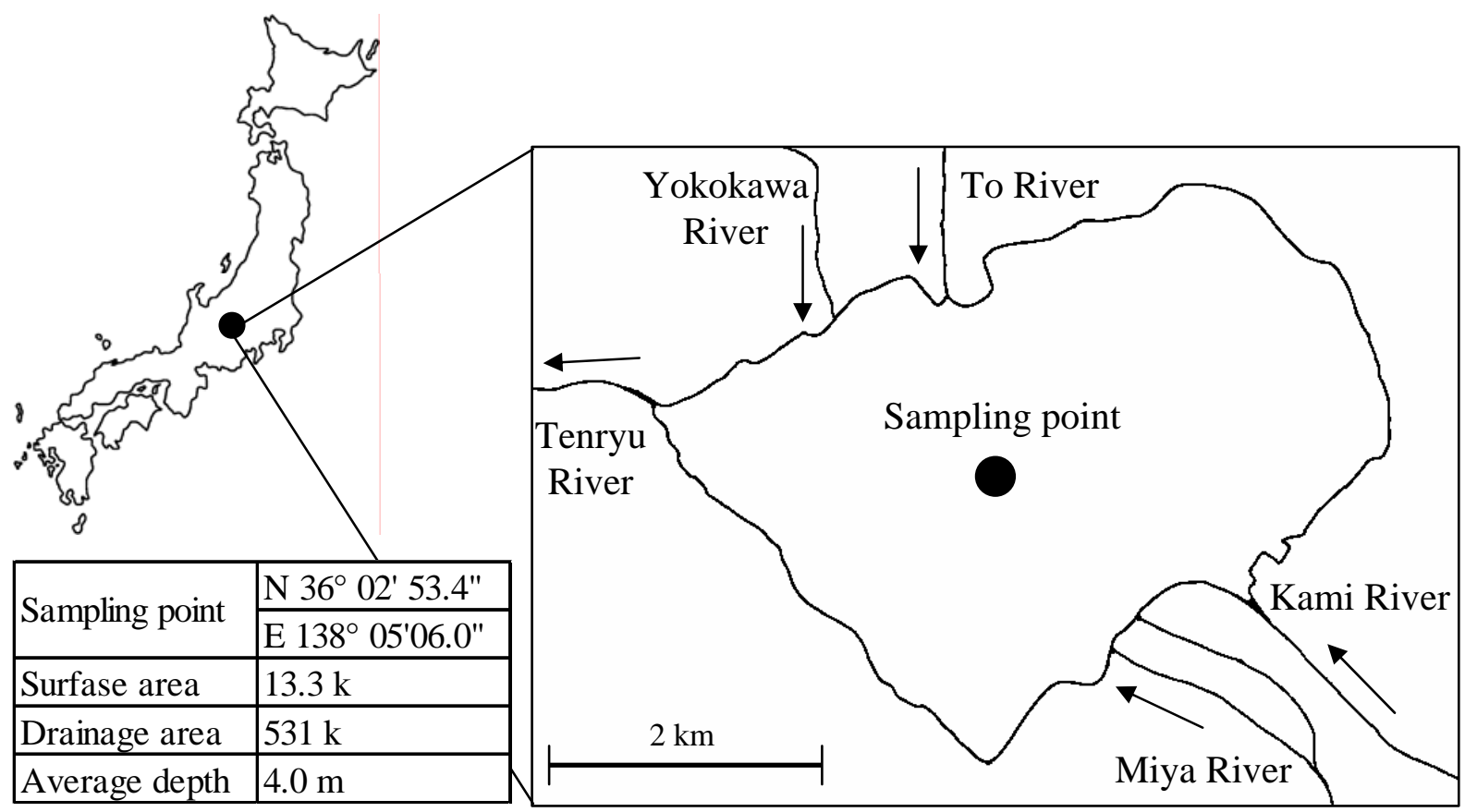

Figure 1. Map of Lake Suwa and the sampling site 


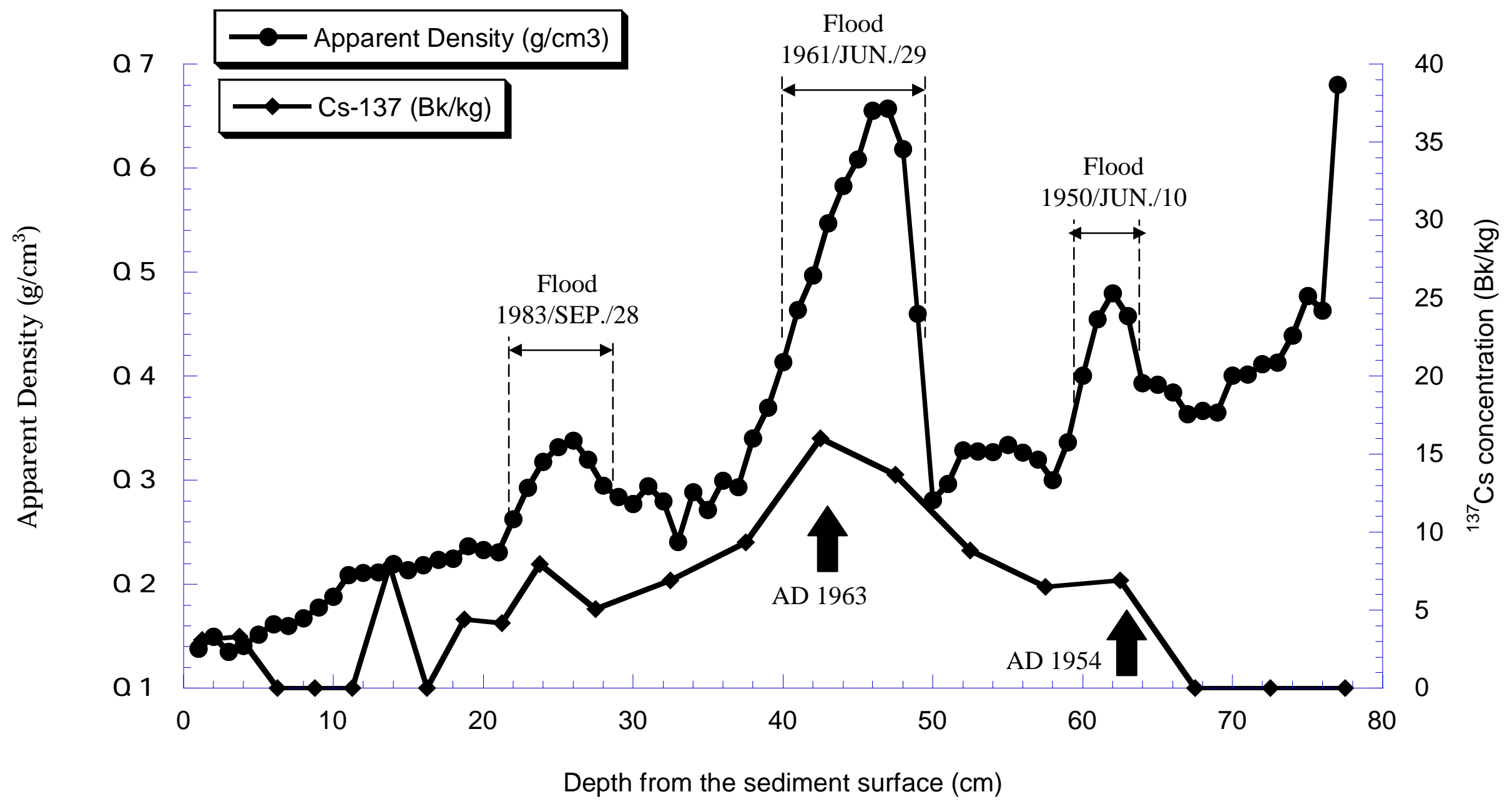

Figure 2. Vertical changes in apparent density of the sediment core 


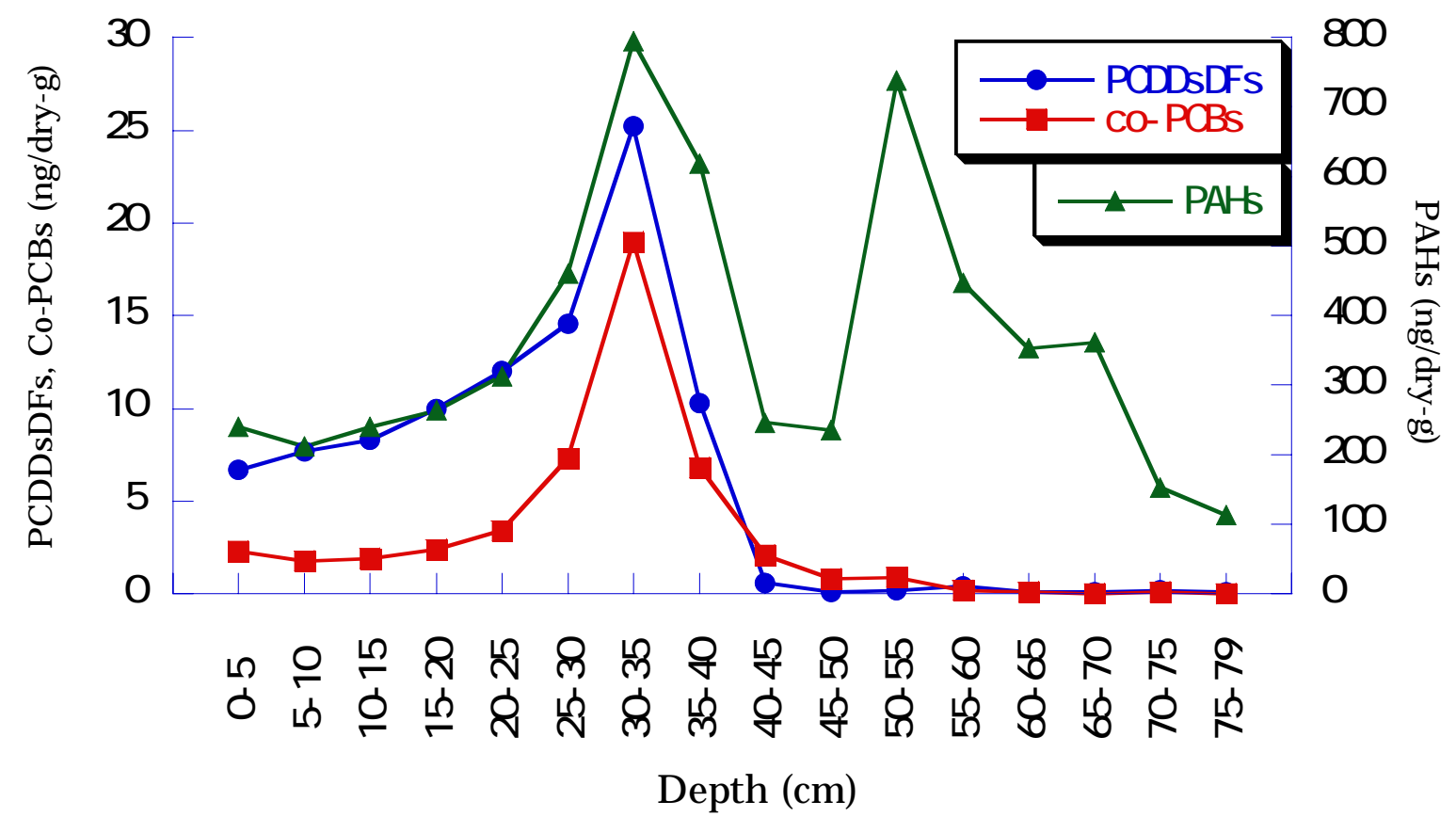

Figure 3. Vertical changes in dioxin and PAH concentrations in the sediment core: (circle) PCDDs/DFs (left scale), (square) co-PCBs (left sale), and (triangle) PAHs (right scale) 


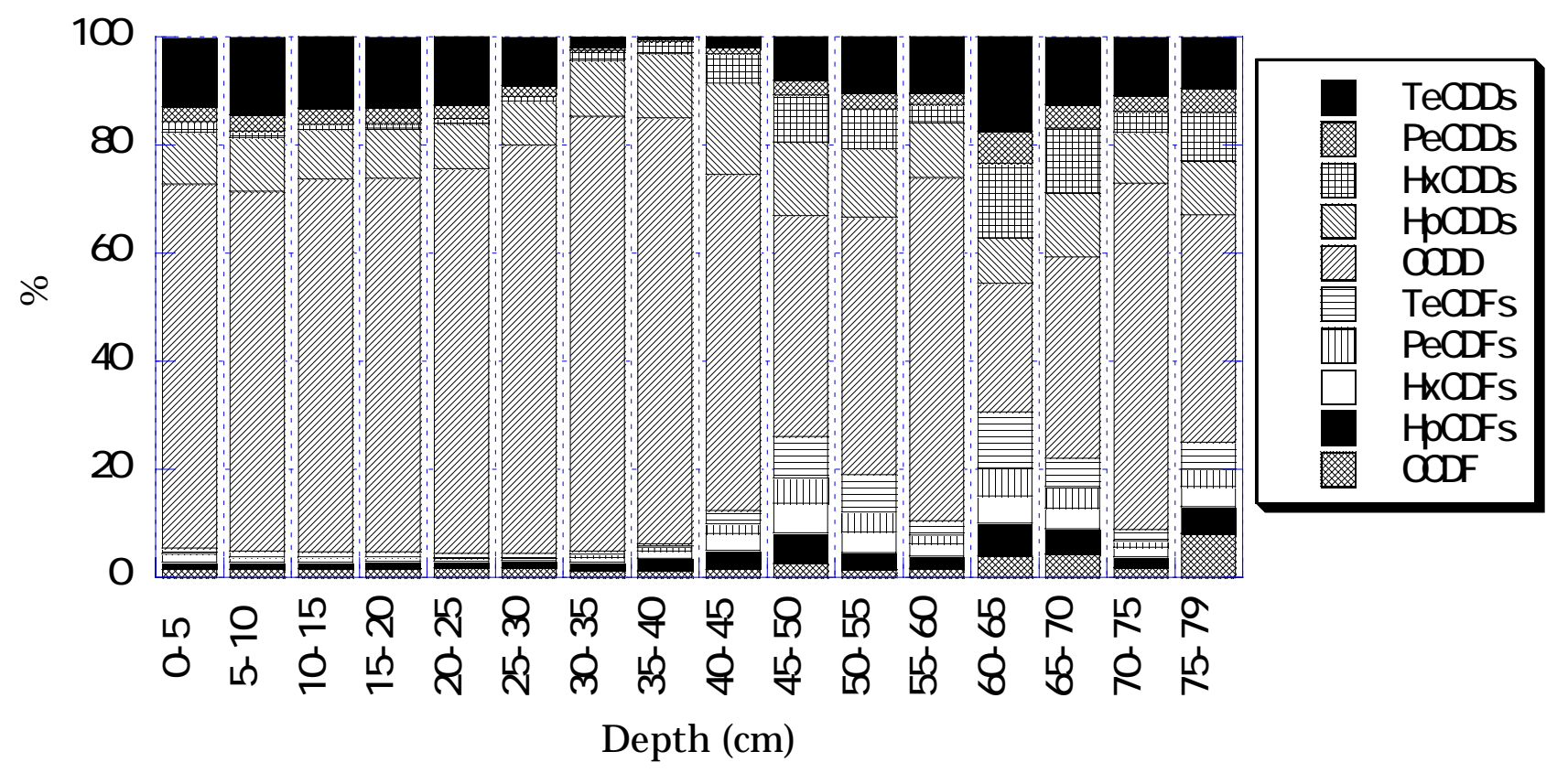

Figure 4. Vertical changes in PCDDs/DFs composition in the sediment core. 


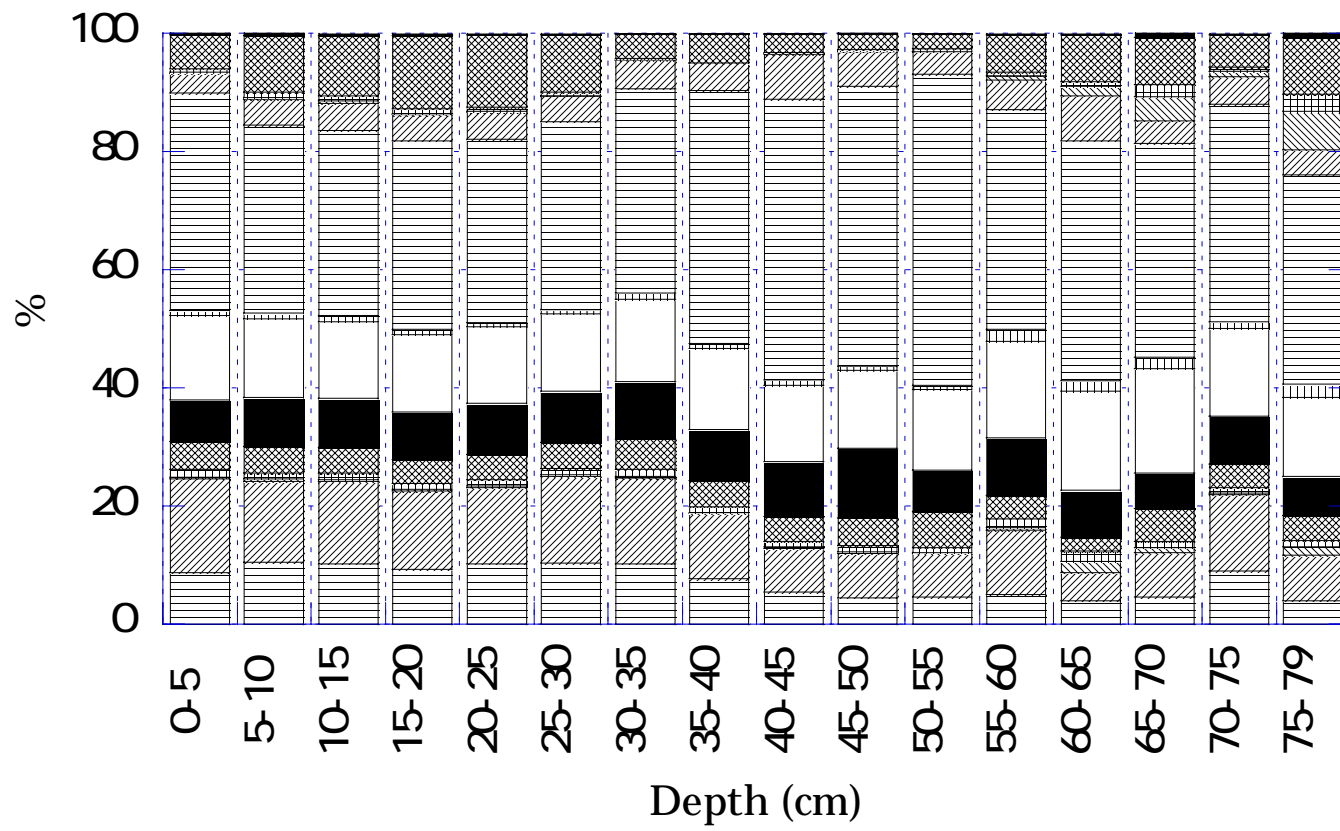

Figure 5. Vertical changes in co-PCBs composition in the sediment core 


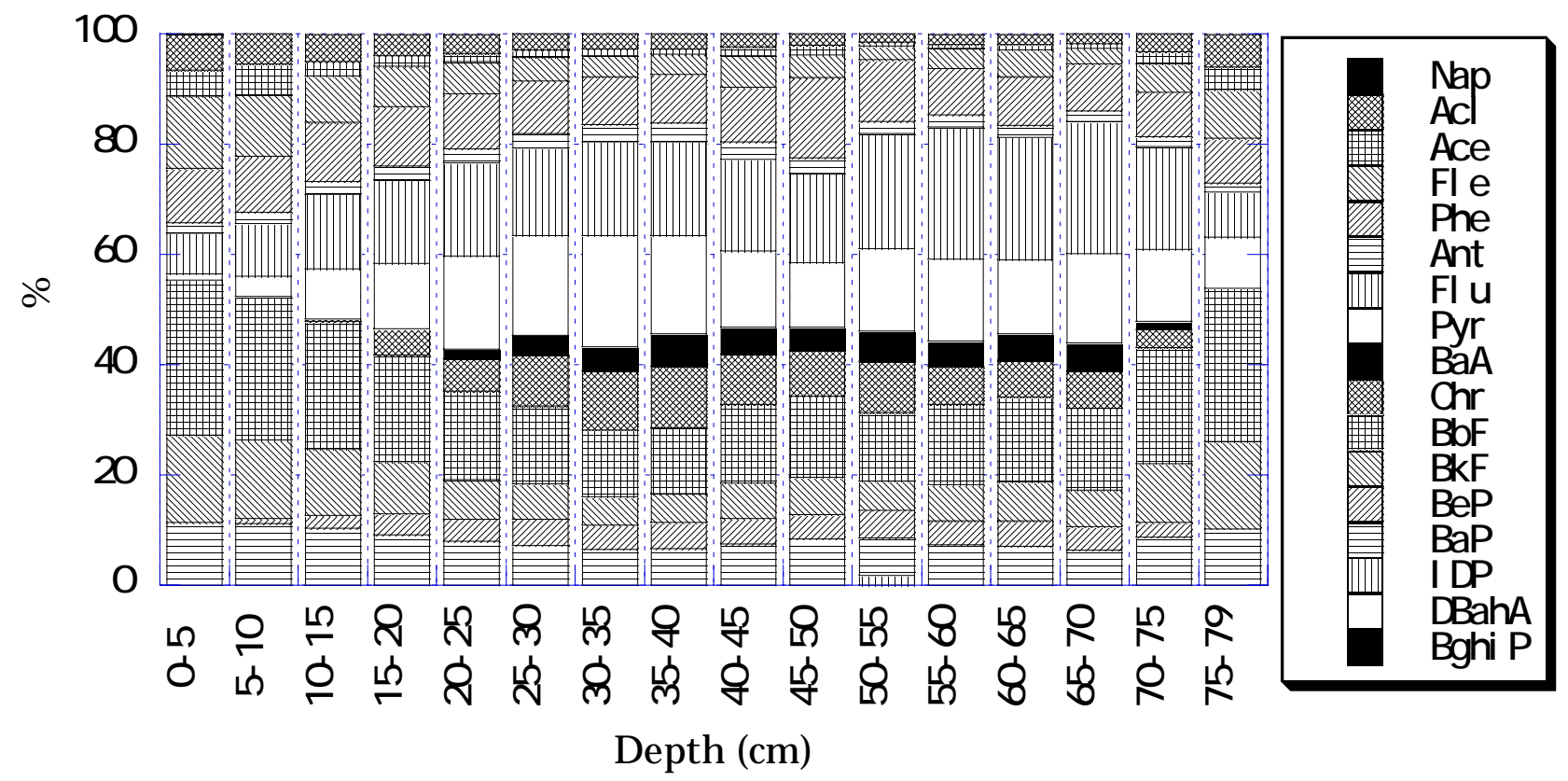

Figure 6. Vertical changes in PAHs composition in the sediment core 